Using the PATHOS questionnaire for screening sexual addiction among college students: A preliminary exploration

By: Craig S. Cashwell, Amanda L. Giordano, Todd F. Lewis, Kate A. Wachtel and Jodi L. Bartley

Cashwell, C. S., Giordano, A. L., Lewis, T. F., Wachtel, K., \& Bartley, J. L. (2015). Using the PATHOS questionnaire for screening sexual addiction among college students: A preliminary exploration. Journal of Sexual Addiction and Compulsivity, 22, 154-166.

Made available courtesy of Routledge: $\underline{\text { htp://dx.doi.org/10.1080/10720162.2015.1037481 }}$

***(C) Routledge. Reprinted with permission. No further reproduction is authorized without written permission from Routledge. This version of the document is not the version of record. Figures and/or pictures may be missing from this format of the document. ***

\begin{abstract}
:
Researchers posit that sexual addiction often develops in young adulthood (Goodman, 2005), the time when many individuals are in college. The PATHOS screening questionnaire (Carnes et al., 2012) may be a helpful resource for counselors working with collegiate populations to identify those in need of further assessment for sexual addiction. We collected data from 379 undergraduate students and found that $21.2 \%$ of males and $6.7 \%$ of females endorsed 3 or more items on the PATHOS, suggesting a need for additional assessment. We discuss implications and limitations of these findings and highlight the need for additional research on college populations.
\end{abstract}

Keywords: sexual addiction | counselors | college | PATHOS screening questionnaire

Article:

***Note: Full text of article below 


\section{Using the PATHOS Questionnaire for Screening Sexual Addiction Among College Students: A Preliminary Exploration}

Craig S. Cashwell, Amanda L. Giordano, Todd F. Lewis, Kate A. Wachtel \& Jodi L. Bartley

To cite this article: Craig S. Cashwell, Amanda L. Giordano, Todd F. Lewis, Kate A. Wachtel \& Jodi L. Bartley (2015) Using the PATHOS Questionnaire for Screening Sexual Addiction Among College Students: A Preliminary Exploration, Sexual Addiction \& Compulsivity, 22:2, 154-166, DOI: $10.1080 / 10720162.2015 .1037481$

To link to this article: http://dx.doi.org/10.1080/10720162.2015.1037481

Published online: 09 Jul 2015.

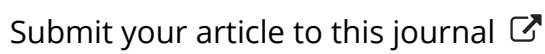

Џll Article views: 43

Q View related articles ๘

View Crossmark data ¿ 


\title{
Using the PATHOS Questionnaire for Screening Sexual Addiction Among College Students: A Preliminary Exploration
}

\author{
CRAIG S. CASHWELL \\ University of North Carolina at Greensboro, Greensboro, North Carolina \\ AMANDA L. GIORDANO \\ University of North Texas, Denton, Texas \\ TODD F. LEWIS \\ North Dakota State University, Fargo, North Dakota \\ KATE A. WACHTEL and JODI L. BARTLEY \\ University of North Carolina at Greensboro, Greensboro, North Carolina
}

\begin{abstract}
Researchers posit that sexual addiction often develops in young adulthood (Goodman, 2005), the time when many individuals are in college. The PATHOS screening questionnaire (Carnes et al., 2012) may be a helpful resource for counselors working with collegiate populations to identify those in need of further assessment for sexual addiction. We collected data from 379 undergraduate students and found that $21.2 \%$ of males and $6.7 \%$ of females endorsed 3 or more items on the PATHOS, suggesting a need for additional assessment. We discuss implications and limitations of these findings and highlight the need for additional research on college populations.
\end{abstract}

A recent definition of addiction by The American Society of Addiction Medicine (ASAM, 2011) included behaviors as potentially addictive processes. Specifically, ASAM's definition of addiction identified sex as a potential addictive behavior, along with eating, gambling, and spending (ASAM, 2011, para. 3). Although not yet recognized as a diagnosis in the Diagnostic and Statistical Manual of Mental Disorders (DSM), the inclusion of sexual behaviors in ASAM's definition reflects the growing acceptance that sex can

Address correspondence to Craig S. Cashwell, Department of Counseling and Educational Development, University of North Carolina at Greensboro, P.O. Box 26170, Greensboro, NC 27402. E-mail: cscashwe@uncg.edu 
become a behavioral addiction. From a neurobiological perspective, it is believed that addictive sexual behavior may be associated with decreased gray matter in the right caudate and decreased functional connectivity of the right caudate to the left dorsolateral prefrontal cortex, suggesting a possible change in neural plasticity related to intense stimulation of the reward system (e.g., by frequent pornography use) along with decreased top-down modulation of prefrontal cortical areas (Kühn \& Gallinat, 2014). Sexual behaviors can trigger the secretion of dopamine in the brain. At intense levels, however, such as with frequent use of pornography, this becomes a supranormal stimulus, a term coined by Tinbergen (1951), that can mirror the effects of drug and alcohol use (Smith, 2012), giving sex the potential to become a substance-less addiction (Blum et al., 2012; Carnes, 1991; Hagedorn \& Juhnke, 2005; Hilton \& Watts, 2011).

Several terms exist to describe out-of-control sexual behaviors, including sexual compulsivity and sexual impulsivity (Goodman, 2001) as well as hypersexual behavior (Reid, Garos, \& Carpenter, 2011). Many researchers, however, have posited that sexual addiction most clearly captures the nature of out of control sexual behavior (Carnes, 2001; Garcia \& Thibaut, 2010; Goodman, 2001; Hagedorn \& Juhnke, 2005; Samenow, 2010) with neuroscience scholars and researchers supporting this assertion (Hilton, 2013; Kühn \& Gallinat, 2014; Voon et al., 2014). Carnes (2001) described sexual addiction as an unhealthy relationship with a "mood-altering experience" (p. 14), suggesting that sex addiction is not about frequency or type of sexual behavior, but rather about a pathological relationship with sexual behaviors that are uncontrollable and persist regardless of harmful consequences. Consistent with this, proposed criteria for a diagnosis of hypersexuality focus on failure to meet goals, activities, and obligations because of recurrent and intense sexual fantasies, urges, and behaviors; repetitive sexual fantasies, urges, or behaviors in response to dysphoric mood states; repetitive sexual fantasies, urges, or behaviors in response to stressful life events; unsuccessful efforts to control or reduce sexual fantasies, urges, or behaviors; repetitive sexual behaviors while disregarding the risk (physical and/or emotional) to others; and clinically significant impairment in some domain (social, occupational, or other) because of sexual fantasies, urges, or behaviors (Kafka, 2010). Symptoms must have occurred for at least 6 months and not be due to the direct physiological effect of an exogenous substance, such as a medication or illegal drug (Kafka).

From these criteria, it becomes evident that sexual addiction, or hypersexuality, is about a preoccupation and ritualization of sexual activity, and an inability to stop or decrease both internal (e.g., preoccupation, fantasy) and external behaviors (e.g., viewing of pornography, paying for sex) in spite of consequences. The cycle of sexual addiction typically consists of four steps including: 1) preoccupation with sexual thoughts, 2) precipitating ritualistic behaviors, 3) engaging in the sexual act, and 4) subsequent feelings of 
despair (Carnes, 2001). The severity of this despair is significant as Carnes (2001) reported that $72 \%$ of those with sexual addiction have contemplated suicide, with $17 \%$ attempting suicide.

It is common for sex addiction to exist concomitant with other addictive behaviors. Researchers have found that $38 \%$ of those with sexual addiction had eating disorders, $42 \%$ had chemical addictions, 28\% engaged in compulsive working, and 26\% struggled with compulsive spending (Carnes, Murray, \& Charpentier, 2005). In many instances, clients may initially present with problems other than sexual addiction that may, in fact, mask the sex addiction. For example, a client may present with ego-dystonic sexual behavior but assert that such behavior only occurs in the presence of heavy alcohol or drug use. After establishing and maintaining sobriety from substances, however, the sexual behaviors may continue, suggesting that substances were not the cause of the sexual behavior, but rather that there was an addiction interaction between the chemical use and sexual behavior, indicating that the person may also have a sexual addiction.

The lack of a uniform diagnosis of sexual addiction also makes it difficult to monitor the prevalence. Despite these challenges, some researchers have posited that 3\% of U.S. adults have a sexual addiction (Sussman, Lisha, \& Griffiths, 2011). In some instances, however, estimates are much higher. For example, Cooper, Morahan-Martin, Mathy, and Maheu (2002) studied online sexual activity among the public and found $19.2 \%$ of the sample were addicted to the internet, sex, or both.

While these figures are helpful in underscoring the prevalence of sexual addiction in general, researchers also must consider unique contexts and subsets of the population. Goodman (2005) noted that sexual addiction typically develops in the teenage years or early twenties, a time when many young adults are in college. Indeed, Seegers (2003) identified 26.1\% of college males as at-risk for sexual addiction or in need of further evaluation and treatment. Therefore, it is necessary to consider the unique attributes of the college environment that may contribute to the development or maintenance of sexual addiction.

\section{Sexual Addiction Among College Students}

College campuses cultivate social environments unlike other contexts across the lifespan. Among the many hallmarks of college, increased alcohol and drug consumption and permissive social norms regarding sexuality contribute to the uniqueness of collegiate culture. Indeed, researchers have found that alcohol use, marijuana use, and sex with multiple partners increased as students transitioned from high school to college (Fromme, Corbin, \& Kruse, 2008). While much of this behavior may be viewed as developmentally normal, sometimes this is not the case. With regard to sexual addiction, the combination of unstructured time, high levels of stress, 
easy access to the internet, frequent use of technology, and opportunities to hook up (a sexual encounter with someone other than a partner in a committed relationship; LaBrie, Hummer, Ghaidarov, Lac, \& Kenney, 2014) may serve to promote compulsive sexual behavior. For example, researchers found that sexting (sending nude or semi-nude pictures via phone; Perkins, Becker, Tehee, \& Mackelprang, 2014) is a prevalent behavior among college students. Reyns, Henson, and Fisher (2014) surveyed undergraduates and determined that $17.4 \%$ sent sext messages and $22.7 \%$ received them during the current academic year. These findings were similar to those reported by Perkins et al. (2014) who determined that 16\% of students sent sexts and $14 \%$ received them in the previous six months.

In addition to sexting, researchers found that a substantial portion of college students viewed internet pornography. Goodson, McCormick, and Evans (2000) found that $43.5 \%$ of college students viewed sexually explicit content on the internet at least one time. Further, these numbers appear to be higher for men. Twohig, Crosby, and Cox (2009) reported that 49\% of a sample of college males reported viewing pornography in the previous 3 months and cited experiencing psychological/spiritual, social, and behavioral problems as a result. Although internet access is a necessary component of most college curricula, with it comes ready access to sexually explicit material for students. While many students may access pornographic material without becoming addicted to it, for others the anonymity, affordability, and accessibility, commonly referred to as the Triple-A Engine (Cooper, 1998) of the internet, contribute to the development of sexually addictive behavior.

Another factor contributing to the sexual climate of college is the prevalence of hooking up. LaBrie et al. (2014) found that $60.1 \%$ of males and $52.2 \%$ of females reported hooking up in the previous year with sexual behaviors ranging from kissing to sexual intercourse with someone who was not a relationship partner. Additionally, Berntson, Hoffman, and Luff (2013) investigated various types of hookups among college students and found that $41 \%$ engaged in a hookup involving sexual intercourse that semester. Those who hooked up in this way typically thought their friends behaved similarly. It appears as though perceptions regarding peers' sexual experiences are important, yet Barriger and Velez-Blasini (2013), determined that students tended to overestimate the frequency of their peers' hookup experiences. For many college students, hooking up behavior may be a part of developmentally normal sexual exploration. For those with a tendency toward sexual addiction, however, hooking up behavior may become compulsive and repetitive, and thoughts of hooking up may become a preoccupation. Perceptions of hooking up norms, hooking up behavior, sexting, internet pornography, and having sex with multiple partners may contribute to the prevalence of addictive sexual behavior among college students (Seegers, 2003). Because little is known about addictive sexual behavior among college students and because of potential consequences of such behavior, there 
is a need for college campuses to effectively screen potentially addictive sexual behavior.

\section{Need for Screening}

The college environment is replete with opportunities to engage in behaviors that may promote the development or maintenance of sexual addiction. Although adolescence is marked by the emergence of sexual cognitions and behaviors and sexual exploration during young adulthood may be developmentally appropriate (Fortenberry, 2013), compulsive sexual behavior is problematic. Researchers found associations between compulsive sexual behavior and higher levels of stress and depression among college students (Odlaug et al., 2013) as well as unprotected sexual practices (Dodge, Reece, Cole, \& Sandfort, 2004). Additionally, sexual preoccupation among students has been correlated significantly with aggression and antisocial behavior (Lee \& Forbey, 2010). Further, sexual addiction can lead to diseases, physical injury, high-risk situations, and unwanted pregnancy, as well as occupational, legal, financial, and relational problems (Carnes, 1991). For students, in particular, excessive time spent preoccupied with sexual activities or engaging in sexual activities (e.g., viewing pornography and masturbating) may negatively impact academic performance.

In light of the potential for sexual addiction among collegiate populations and associated negative consequences, it seems imperative for professionals working with college students to assess for sexual addiction. Recently, however, researchers reported that only $12.8 \%$ of college counseling center websites mentioned sexual compulsivity, although 60-80\% addressed issues such as substance abuse, depression, disordered eating, and stress (Wright \& McKinley, 2010). Therefore, students experiencing sexual addiction may not know where to find the help and resources they need. Additionally, helping professionals may be unprepared to identify and address sexual addiction among collegiate clients. One step toward remedying this issue is to implement effective assessment strategies that serve to identify students in need of further treatment for sexual addiction. For example, the Sexual Addiction Screening Test-Revised (SAST-R; Carnes, Green, \& Carnes, 2010) is a 45-item measure used to assess sexual addiction by examining level of preoccupation, loss of control, and affective and relational disturbances. The SAST-R is available online (http://www.recoveryzone.com/tests/sexaddiction/SAST/index.php) with immediate scoring feedback. In a college setting, however, an even more brief screening tool may be helpful to determine the need for further assessment. The PATHOS questionnaire (Carnes et al., 2012) is comprised of 6 questions to assess potential for sexual addiction. Each question was taken from the SAST-R and addresses an element of sexual addiction (P: preoccupied; A: ashamed; T: treatment; H: hurt others; O: out of control; and S: sad). An affirmative response to 3 or more items 
indicates the need for further evaluation. We believe the PATHOS can be a helpful tool for professionals working with college students in order to identify those who may have a sexual addiction. The purpose of the current study was to utilize the PATHOS questionnaire with two college student samples in different geographic locations in order to determine the prevalence of students meeting criteria for further evaluation.

\section{METHODS}

Procedure

Researchers have identified problematic sexual behaviors among both males (Lee, Ritchey, Forbey, \& Gaither, 2009; Reid, Harper, \& Anderson, 2009) and females (Seegers, 2003). Therefore, we sought to investigate the results of the PATHOS questionnaire among male and female college students. The student populations at both participating institutions were predominantly female, so we intentionally sampled from math and science classes to attain a robust number of male participants. We received IRB approval from both institutions and contacted course instructors for permission to administer the survey during class time. We collected data from 11 undergraduate classes in the fields of math, science, and education.

\section{Participants}

Data collection yielded 379 surveys from two large, public universities in the south. Inclusion criteria for study participants consisted of undergraduate status and at least 18 years of age. Participants averaged 21.24 $(S D=3.93)$ years old and were 44.9\% $(n=170)$ male and 55.1\% $(n=209)$ female. With regard to race/ethnicity, $48.3 \%$ identified as White ( $n=183), 31.1 \%$ identified as Black/African American $(n=118), 9.2 \%$ identified as Latino $(n=35), 5.8 \%$ identified as Asian-American $(n=22), 2.9 \%$ identified as other $(n=11), 1.3 \%$ identified as Native American $(n=5)$, and $1.3 \%$ identified as Multi-racial $(n=5)$.

\section{Measures}

Participants completed a short demographics questionnaire assessing age, gender, and race/ethnicity. While data collection at both institutions included the PATHOS measure, participants also completed multiple assessment instruments that were used for two distinct studies. At one institution, the survey packet took approximately 15 minutes to complete and at the other institution, completion time was approximately 25-30 minutes. 


\section{PATHOS}

The PATHOS (Carnes et al., 2012) was developed as a brief screening tool for assessing sexual addiction. PATHOS (Greek for suffering) is an acronym for the 6-item assessment. The six PATHOS items were extracted from the Sexual Addiction Screening Test (SAST; Carnes, 1989).

The 6 items are:

1. Do you often find yourself preoccupied with sexual thoughts? [Preoccupied]

2. Do you hide some of your sexual behavior from others? [Ashamed]

3. Have you ever sought help for sexual behavior you did not like? [Treatment]

4. Has anyone been hurt emotionally because of your sexual behavior? [Hurt others]

5. Do you feel controlled by your sexual desire? [Out of control]

6. When you have sex, do you feel depressed afterwards? [Sad]

The PATHOS assessment scores have been found to have acceptable internal consistency (KR-20 $=.77$ for men, .81 for women) among a sample of 913 participants from three populations (outpatient treatment for sex addiction, residential treatment for sex addiction, undergraduate college students) (Carnes et al., 2012). Interestingly, the estimate of internal consistency for the current sample was lower $(\mathrm{KR}-20=.51)$ for the total sample. In a large sample of 1,771 participants, Carnes et al. (2012) found through ROC analyses that the PATHOS achieved $88.3 \%$ sensitivity (true positive results) and $81.6 \%$ specificity (true negative results) for the male sample $(n=963)$ and $80.9 \%$ sensitivity and $87.2 \%$ specificity for the female sample $(n=808)$ using a cut-off score of 3 . Carnes et al. (2012) concluded that the PATHOS questionnaire can be useful to identify individuals who may benefit from additional assessment of sexual addiction symptoms and may provide a rough index of case severity. That is, these six items are not intended to determine a diagnosis of sex addiction, but rather indicate the detection of potential sexual addiction (Carnes et al., 2012) and the need for additional assessment.

To date, the PATHOS assessment has been studied primarily with clinical populations and it was unknown how the instrument would work with a broader population (i.e., college students). For example, the $T$ in PATHOS stands for Treatment and the concomitant question is Have you ever sought help for sexual behavior you did not like? Many undergraduate college students who engage in addictive sexual behavior may not yet have incurred negative consequences sufficient for them to seek treatment (P. Carnes, personal communication, November 9, 2012). Even with the caveat that few participants were likely to endorse the Treatment question positively, 
TABLE 1 Endorsement of PATHOS Items by Sex

\begin{tabular}{lcc}
\hline Item & Men $(\mathrm{n}=170)$ & Women $(\mathrm{n}=209)$ \\
\hline Preoccupied & $86(50.6 \%)$ & $51(24.4 \%)$ \\
Ashamed & $97(57.1 \%)$ & $97(46.4 \%)$ \\
Treatment & $13(7.6 \%)$ & $7(3.3 \%)$ \\
Hurt Others & $35(20.6 \%)$ & $25(12.0 \%)$ \\
Out of Control & $24(14.1 \%)$ & $9(4.3 \%)$ \\
Sad & $14(8.2 \%)$ & $11(5.3 \%)$ \\
\hline
\end{tabular}

Note. Each item corresponded with a dichotomous yes or no answer choice.

a decision was made to use the original cut-off of 3 to identify participants with potential sexual addiction who would warrant additional assessment.

\section{RESULTS}

The researchers entered the data from 379 college students into SPSS and analyzed gender differences using a $z$-test. Out of the 170 men in the sample, $36(21.2 \%)$ scored a 3 or above on the PATHOS, and 14 of the 209 women (6.7\%) scored a 3 or above. Results of the z-test indicated significant differences between frequencies reported by men and women $(z=4.11, p<.01)$, indicating the men were significantly more likely to endorse three or more items on the PATHOS than were women. Additionally, although individual items are not diagnostic in and of themselves, for heuristic purposes, given the exploratory nature of this study, we examined the frequencies of individuals endorsing specific PATHOS based on biological sex. These results are presented in Table 1 . As anticipated, a very small percentage of participants $(n=20,5.3 \%)$ endorsed the Treatment item, indicating that they had sought professional help for sexual behavior. Over half of the men in the sample reported being preoccupied with (50.6\%) and ashamed of (57.1\%) sexual behavior. These same two items received the highest endorsement by women, albeit at lower rates.

\section{DISCUSSION}

The most notable finding from this study was that over $20 \%$ of men who participated and almost $7 \%$ of women who participated met the clinical threshold of a score of 3 on the PATHOS quick screening instrument in spite of the fact that, as anticipated, very few participants endorsed the Treatment item. This low endorsement was anticipated and likely is an artifact of not yet facing consequences of sexual behavior substantive enough to warrant 
professional mental services. We do not propose that all participants who scored at or above the clinical cutoff of 3 have a sexual addiction but the results do indicate that these participants would benefit from additional screening. What percentage of these participants ultimately have, or will develop, a sexual addiction is beyond the scope of this study. Nonetheless, the finding that over 1 in 5 men and almost 1 in 16 women scored at or above the clinical cutoff for the PATHOS assessment suggests that there are substantive problematic sexual behaviors and it seems logical that some would elevate to the level of meeting criteria for sexual addiction. Over half of the men who participated in this study endorsed both the Preoccupation (50.6\%) and Ashamed (57.1\%) items. This is noteworthy because shame is considered fuel for the addictive cycle as it leads to preoccupation and ritualization of sexual behavior. This shame potentially perpetuates a negative cycle where the individual engages in sexual behavior to relieve dysphoric mood states caused or increased by the shame and preoccupation, thereby creating more shame. The resulting negative self-perpetuating cycle can grow more powerful over time, occasioning sexual behaviors that increase in frequency, duration, number, or intensity.

The finding that over $20 \%$ of male participants warrant further assessment and may be high-risk for sexual addiction is consistent with Seegers' (2003) results in which $26.1 \%$ of college males may have developed, or be at risk of developing, addictive sexual behavior as assessed by the Hypersexual Behavior Inventory (HBI; Reid et al., 2011). The implications of these findings are clear; counselors working with collegiate populations must be familiar with sexual addiction and effective screening measures in order to provide appropriate services. Graduate level education related to the treatment of sexual addiction would prepare competent clinicians to identify and address students with problematic sexual behavior. Unfortunately, Hagedorn (2009) found that among a sample of substance abuse counselors and sexual addiction therapists, only $7.5 \%$ received graduate education related to assessing and treating sexual addiction. The majority of participants (57.4\%) reported that they never experienced a discussion of sexual addiction during their graduate programs. Given the prevalence of students requiring additional assessment for sexual addiction, our study provides support for the implementation of formal education in this area.

Another implication of our findings is the need for clear marketing regarding sexual addiction treatment services on college campuses. Wright and McKinley (2010) found that the majority of college campuses do not market services for addictive sexual behaviors despite marketing services for substance and other behavioral addictions. Therefore, college campuses seem poorly positioned to address addictive sexual behavior and students desiring help may not know where to access services. University counseling centers, in particular, would be well served to increase their visibility on campus in terms of programming and services around addictive sexual behaviors. 
The results of the current study must be contextualized within study limitations. The sample was one of convenience, drawn from intact classrooms at two large public universities in the southern United States. It is unknown to what extent this limits the generalizability of these findings. Although the majority of the students in these classrooms participated, it is unknown how non-participants may differ from participants, how the students in the classrooms selected may differ systematically from other students in the university, and how these findings might generalize to other settings (e.g., private and religious universities and other geographic areas).

Additionally, all data from this study were generated by self-report, creating a mono-method bias. Given this, future researchers might consider using an additional screening (such as the SAST-R; Carnes et al., 2010) and consider correlations between the PATHOS and SAST-R scores. Additionally, the questions asked of participants potentially had socially desirable responses. Although questions about particular sexual behaviors might lead some participants to inflate their responses, it is important to keep in mind that the questions asked of participants were not about sexual behaviors but about consequences of sexual behaviors. It is unlikely that social desirability would lead a participant to inflate their responses to such questions. In fact, it seems far more likely, given issues of denial, minimization, justification, and rationalization inherent in addictive behaviors (Howard et al., 2002), that people would deflate their responses, so the potential exists for even more widespread problems than indicated by these results.

Further, it will be important for future researchers to consider the developmental context within which the PATHOS questions are being asked. For example, asking an unmarried college student whether he or she hides sexual behavior from others may be quite different from asking the same question of someone who is partnered and has children. Students may be reporting hiding sexual behavior from parents or guardians, which is a very different boundary from hiding sexual behavior within an intimate committed partnership.

Finally, the estimate of the internal reliability for the PATHOS assessment was lower for this sample than was found with the norm group, even though the norm group did include undergraduate college students. It is unknown whether this is an artifact of this potential sample or whether there are issues related to using the PATHOS with college students. Further research is warranted to examine this issue more fully.

\section{CONCLUSION}

Results of the current study suggest a substantial percentage of college students are at-risk for addictive sexual behavior and warrant additional assessment. The PATHOS screening questionnaire may be an effective tool for 
clinicians working with collegiate populations to identify those students in need of additional assessment for sexual addiction. It is critical that university systems respond to this issue, as early detection and intervention during the college years could be critical to helping students develop healthier coping strategies to deal with stressors of the college environment and develop sexually in a way that is healthy and ego-syntonic.

\section{REFERENCES}

American Society of Addiction Medicine (ASAM) (2011). Public policy statement: Definition of addiction. Retrieved from http://www.asam.org/for-thepublic/definition-of-addiction

Barriger, M., \& Velez-Blasini, C. J. (2013). Descriptive and injunctive social norm overestimation in hooking up and their role as predictors of hook-up activity in a college student sample. Journal of Sex Research, 50, 84-94. doi:10.1080/00224499.2011.607928

Berntson, M. A., Hoffman, K. L., \& Luff, T. L. (2014). College as context: Influences on interpersonal sexual scripts. Sexuality \& Culture, 18, 149-165. doi:10.1007/s12119-013.9180-7

Blum, K., Werner, T., Carnes, S., Carnes, P., Bowirrat, A., Giordano, J., . . . Gold, M. (2012). Sex, drugs, and rock 'n' roll: Hypothesizing common mesolimbic activation as a function of reward gene polymorphisms. Journal of Psychoactive Drugs, 44, 1-18.

Carnes, P. J. (1989). Contrary to love: Helping the sexual addict. Center City, MN: Hazelden.

Carnes, P. (1991). Don't call it love: Recovery from sexual addiction. New York, NY: Bantam Books.

Carnes, P. (2001). Out of the shadows: Understanding sexual addiction (3rd ed.). Center City, MN: Hazelden.

Carnes, P., Green, B., \& Carnes, S. (2010). The same yet different: Refocusing the Sexual Addiction Screening Test (SAST) to reflect orientation and gender. Sexual Addiction \& Compulsivity, 17, 7-30. doi:10.1080/10720161003604084

Carnes, P. J., Green, B. A., Merlo, L. J., Polles, A., Carnes, S., \& Gold, M. S. (2012). PATHOS: A brief screening application for assessing sexual addiction. Journal of Addiction Medicine, 6, 29-34. doi:10.1097/ADM.ob013e313182251a28

Carnes, P. J., Murray, R. E., \& Charpentier, L. (2005). Bargains with chaos: Sex addicts and addiction interaction disorder. Sexual Addiction \& Compulsivity, 12, 79-120. doi:10.1080/10720160500201371

Cooper, A. (1998). Sexuality and the internet: Surfing into the new millennium. CyberPsychology \& Behavior, 1, 181-187.

Cooper, A., Morahan-Martin, J., Mathy, R. M., \& Maheu, M. (2002). Toward an increased understanding of user demographics in online sexual activities. Journal of Sex \& Marital Therapy, 28, 105-129. doi:10.1080/00926230252851861

Dodge, B., Reece, M., Cole, S. L., \& Sandfort, T. G. M. (2004). Sexual compulsivity among heterosexual college students. Journal of Sex Research, 41, 343-350. 
Fortenberry, J. D. (2013). Sexual development in adolescents. In D. S. Bromberg \& W. T. O'Donohue (Eds.). Handbook of child and adolescent sexuality: Developmental and forensic psychology (pp. 171-192). London, UK: Elsevier

Fromme, K., Corbin, W. R., \& Kruse, M. I. (2008). Behavioral risks during the transition from high school to college. Developmental Psychology, 44, 1497-1504. doi:10.1037/a0012614

Garcia, F. D., \& Thibaut, F. (2010). Sexual addictions. American Journal of Drug \& Alcohol Abuse, 36, 254-260. doi:10.3109/00952990.2010.503823

Goodman, A. (2001). What's in a name? Terminology for designating a syndrome of driven sexual behavior. Sexual Addiction \& Compulsivity, 8, 191-213. doi:10.1080/107201601743459919

Goodman, A. (2005). Sexual addiction: Nosology, diagnosis, etiology, and treatment. In J. H. Lowinson, P. Ruiz, R. B. Millman, \& J. G. Langrod (Eds.). Substance abuse: A comprebensive textbook (4th ed.). (504-539). Philadelphia, PA: Lippincoll Williams \& Wilkins.

Goodson, P., McCormick, D., \& Evans, A. (2000). Sex on the internet: College students' emotional arousal when viewing sexually explicit materials on-line. Journal of Sex Education \& Therapy, 25, 252-260

Hagedorn, B. W. (2009). Preparing competent clinicians: Curricular applications based on the sexual addiction counseling competencies. Sexual Addiction \& Compulsivity, 16, 341-360. doi:10.1080/10720160903399855

Hagedorn, B. W., \& Juhnke, G. A. (2005). Treating the sexually addicted client: Establishing a need for increased counselor awareness. Journal of Addiction and Offender Counseling, 25, 66-86.

Hilton, D. L. (2013). Pornography addiction-a supranormal stimulus considered in the context of neuroplasticity. Socioaffective Neuroscience $\varepsilon$ Psychology, 3. Retrieved from http://www.socioaffectiveneuroscipsychol.net/ index.php/snp/article/view/20767

Hilton, D. L., \& Watts, C. (2011). Pornography addiction: A neuroscience perspective. Surgical Neurology International, 2. Retrieved from http://www.ncbi.nlm.nih.gov/pmc/articles/PMC3050060/

Howard, M., McMillen, C., Nower, L., Elze, D., Edmond, T., \& Bricout, J. (2002). Denial in addiction: Towards an integrated stage and process model—qualitative findings. Journal of Psychoactive Drugs, 34, 371-382.

Kafka, M. P. (2010). Hypersexual disorder: A proposed diagnosis for DSM-V. Archives of Sexual Behavior, 39, 377-400. doi;10.1007/s10508-009-9574-7

Kühn, S., \& Gallinat, J. (2014). Brain structure and functional connectivity associated with pornography consumption: The brain on porn. JAMA Psychiatry. doi:10.1001/jamapsychiatry.2014.9.

LaBrie, J. W., Hummer, J. F., Ghaidarov, T. M., Lac, A., \& Kenney, S. R. (2014). Hooking up in the college context: The event-level effects of alcohol use and partner familiarity on hookup behaviors and contentment. Journal of Sex Research, 51, 62-73. doi:10.1080/00224499.2012.714010

Lee, T., \& Forbey, J. D. (2010). MMPI-2 correlates of sexual preoccupation as measured by the sexuality scale in a college setting. Sexual Compulsivity \& Compulsivity, 17, 219-235. doi:10.1080/10720162.2010.500500

Lee, T. T. C., Ritchey, K. A., Forbey, J. D., \& Gaither, G. A. (2009). Psychometrics and comparison of the Compulsive Sexual Behavior Inventory and the 
Sexual Compulsivity Scale in a male college student sample. Sexual Addiction E Compulsivity, 16, 146-167. doi:10.1080/10720160902905512

Odlaug, B. L., Lust, K., Schreiber, L. R. N., Christenson, G., Derbyshire, K., Harvanko, A., ... Grant, J. E. (2013). Compulsive sexual behavior in young adults. Annals of Clinical Psychiatry, 25, 193-200.

Perkins, A. B., Becker, J. V., Tehee, M., \& Mackelprang, E. (2014). Sexting behaviors among college students: Cause for concern? International Journal of Sexual Health, 26, 79-92. doi:10.1080/19317611.2013.841792

Reid, R. C., Garos, S., \& Carpenter, B. N. (2011). Reliability, validity, and psychometric development of the Hypersexual Behavior Inventory in an outpatient sample of men. Sexual Addiction \& Compulsivity, 18, 30-51. doi:10.1080/10720162.2011.555709

Reid, R. C., Harper, J. M., \& Anderson, E. H. (2009). Coping strategies used by hypersexual patients to defend against the painful effects of shame. Clinical Psychology \& Psychotherapy, 16, 125-138. doi:10.1002/cpp.609

Reyns, B. W., Henson, B., \& Fisher, B. S. (2014). Digital deviance: Low self-control and opportunity as explanations of sexting among college students. Sociological Spectrum, 34, 273-292. doi:10.1080/02732173.2014.895642

Samenow, C. P. (2010). Classifying problematic sexual behaviors-It's all in the name. Sexual Addiction \& Compulsivity, 17, 3-6. doi:10.1080/10720161003697073

Seegers, J. A. (2003). The prevalence of sexual addiction symptoms on the college campus. Sexual Addiction \& Compulsivity, 10, 247-258. doi:10.1080/10720160390268942

Smith, D. E. (2012). The process addiction and the new ASAM definition of addiction. Journal of Psychoactive Drugs, 44, 1-4. doi:10.1080/02791072.2012.662105

Sussman, S., Lisha, N., \& Griffiths, M. (2011). Prevalence of the addictions: A problem of the majority or the minority? Evaluation \& the Health Professions, 34, 3-56. doi: $10.1177 / 0163278710380124$

Tinbergen, N. (1951). The study of instinct. Oxford, UK: Clarendon Press.

Twohig, M. P., Crosby, J. M., \& Cox, J. M. (2009). Viewing internet pornography: For whom is it problematic, how, and why? Sexual Addiction \& Compulsivity, 16, 253-266. doi:10.1080/10720160903300788

Voon, V., Mole, T. B., Banca, P., Porter, L., Morris, L., Mitchell, S., . . . Irvine, M. (2014). Neural correlates of sexual cue reactivity in individuals with and without compulsive sexual behaviours. PLoS One, 9. Retrieved from http://www.ncbi.nlm.nih.gov.libproxy.uncg.edu/pmc/articles/PMC4094516/

Wright, P. J., \& McKinley, C. J. (2010). Services and information for sexually compulsive students on college counseling center websites: Results from a national sample. Journal of Health Communication, 15, 665-678. doi:10.1080/10810730.2010.499596 